\title{
Survival and Years of Good Life in Finland in the very long run
}

\author{
CLAUDIA REITER \\ WOLFGANG LUTZ
}

Wittgenstein Centre for Demography and Global Human Capital (Univ.Vienna, IIASA, VID/OeAW), International Institute for Applied Systems Analysis, Schlossplatz 1, 2361 Laxenburg, Austria.

\section{Abstract}

In this paper we apply the recently developed wellbeing indicator 'Years of Good Life' (YoGL) to Finland, which has the world's longest annual demographic time series starting in 1722. We combine this with scenarios up to 2100 as developed under the SSP (Shared Socioeconomic Pathways) framework. YoGL is based primarily on the trend in life expectancy but it also considers age-specific proportions of persons above critical levels of quality of life indicators (using the Sullivan method). Since estimating these indicators for historical populations is a major challenge, the paper uses a wide array of sources to come up with a first crude estimation of how quality of life has changed in Finland over the centuries.

Keywords: Years of Good Life; wellbeing indicator; quality of life; Shared Socioeconomic Pathways

\section{Introduction}

It may not be widely known that Finland has the world's longest annual national demographic time series starting in 1722. While Iceland is credited for having had in 1703 the first complete census of any country existing today, this has not been followed up by published annual statistics on vital rates. In the whole of the Swedish kingdom (to which Finland belonged in the $18^{\text {th }}$ century), both population counts and annual vital statistics based on parish registers were systematically introduced with the Tabellverked in 1749. However, based on collections of annual parish reports to the diocesan church authorities, earlier trends could be estimated for parts of the country as published by Jutikkala (1965) for the territory of today's Finland from 1722 onwards.

The systematic recording of all baptisms, marriages, and funerals has been already introduced with the church laws of 1628 , which were reinforced through new laws in 
1686 (Nieminen 1999). Due to the hostilities and resulting devastation in the Great Northern War, most of the relevant church books up to 1721 have been lost. Only after the 1721 peace treaty of Uusikaupunki (Swedish Nystad), which ended the war, comprehensive systematic data were available as later published by Jutikkala (1965). This direct link to the 1721 Uusikaupunki peace treaty also motivated the production of this paper for the Uusikaupunki Peace Symposium 2019 on "Peace and Sustainable Development" in preparation for the 300-year anniversary in 2021. This topic of the symposium also links to another strain of research focusing on the trends in human wellbeing over time as a criterion for judging whether a development can be considered as sustainable or not. This research question of sustainability science also requires a long view into the future to assess the possible repercussions of environmental and other changes caused today on future human wellbeing in different parts of the world.

At the heart of this research on sustainable human wellbeing lies the need for an indicator of human wellbeing whose trend over longer time periods can be assessed and can be used as sustainability criterion in the sense that it should not decline over time in any subpopulation, even when feedbacks from environmental, economic, or other relevant changes are factored in. While this highly ambitious project is still in its early phase and no formal modelling of these feedbacks yet exists, in this paper we rely on a set of comprehensive global scenarios to 2100 that are widely used in the field of climate change analysis, namely the SSPs (Shared Socioeconomic Pathways), which provide alternative, consistent scenarios on several socioeconomic indicators following contrasting narratives for all countries (O’Neill et al. 2014; Riahi et al. 2017).

When studying future challenges one can always learn from the past. Hence, when trying to better understand the challenges for long term future human wellbeing, it seems to be a useful approach to also have a look at the longest possible historical time series of death rates, survival, and years lived in acceptable quality of life. In this sense, this paper does not attempt to present a thorough and critical analysis of the different sources of historical data and their validity but to put together very different data sources published in the literature in a selective and rather opportunistic way with the main goal to produce a first rough estimate of such a very long time series of Years of Good Life lived in Finland over the centuries.

Finland not only offers a long demographic time series but also a particularly interesting story of increasing quality of life. Up to the late $19^{\text {th }}$ century, Finland was one of the poorest corners of Europe. The backward and fully agrarian economy was exposed to poor climate conditions and had virtually no natural resources except for slowly growing trees. In 1867-1868, Finland experienced Europe's last major peacetime famine, losing roughly one tenth of its population to starvation (Voutilainen 2016). Only 150 years later, Finland is known for its efficient economy, its generous and wellfunctioning welfare system, its advanced educational system, and is home to companies of worldwide repute (Ojala, Eloranta, \& Jalava 2006). The highly advanced and innovative industrial country was ranked by assorted international indices the happiest, most stable, safest, and best-governed country in the world (Statistics Finland 2018). 
Recently, a number of studies have tried to understand the reasons for this remarkable success story (see for example Koponen \& Saaritsa 2019; Haapala 2018; Kokkinen 2012; Ojala et al. 2006, etc.). Kokkinen (2012), for instance, found that rather than by explanations provided by conventional neo-classical growth and convergence models, the impressive catch-up of Finland can be explained by technology diffusion combined with immense investments in human capital, where technological progress is embodied in the new varieties of fixed capital. In the comprehensive economic history book "The road to prosperity", leading Finnish economic and social science historians explore Finland's rags-to-riches success story alongside different key themes, concluding that the "Finnish model" has been characterized by egalitarianism, a strong government role, innovativeness and geopolitical adjustment. Similarly, Koponen and Saaritsa (2019) outline Finland's economic and social development in their recently edited book, highlighting the role of foreign investment, technology diffusion and well-functioning institutions. But before trying to explain historical trends and improvements, we need to be more precise about the dependent variable. While most of the above cited studies have looked at GDP per person, several other indicators of wellbeing have been suggested recently. Therefore, the first relevant question that arises in this regard is: the improvement of what exactly should be explained?

In this paper, we try to elaborate on the definition of such a dependent variable in the form of a general and widely acceptable indicator of human wellbeing that is richer and more relevant than the heavily criticized but still widely used GDP per person (Stiglitz, Sen, \& Fitoussi 2009). In Section 2, we first provide for readers not so familiar with Finland some general background information about Finland's economic and population history and the country's demographic data availability. In Section 3, the methodological foundations of the newly introduced indicator Years of Good Life (YoGL) in general (3.1) and for the historical reconstruction of YoGL in Finland (3.2) are discussed. Moreover, the chapter provides a detailed account of all data and indicators used for the historical reconstruction of YoGL. Application and results of YoGL estimates for Finland can be found in Section 4. Finally, we conclude with a discussion about our findings and give an outlook of possible future studies to use this long time series of YoGL with the aim of better understanding the story of Finland since the $18^{\text {th }}$ century.

\section{Background}

Finland gained independence in 1917, after being a part of imperial Russia since 1809, and before that a part of Sweden. Since January 1995, Finland is a member state of the European Union (EU). Although being the fifth largest country in the EU with a total land area of $304,473 \mathrm{~km}^{2}$, Finland only ranks 18 in terms of population size (5.5 million), making it the most sparsely populated country in the EU (Eurostat 2019). Population density has been low throughout Finnish history: in the mid- $18^{\text {th }}$ century, it was 
Table 1: Finnish economic growth (real GDP per capita in 2011 USD) in comparison with selected countries, $1820-2000$

\begin{tabular}{|r|r|r|r|r|r|r} 
& Finland & \multicolumn{1}{c|}{ UK } & \multicolumn{1}{c|}{ USA } & France & Sweden & Netherlands \\
\hline $\mathbf{1 8 2 0}$ & $\mathbf{8 9 5}$ & 2,181 & 2,080 & 1,442 & 1,192 & 1,724 \\
\hline $\mathbf{1 8 5 0}$ & $\mathbf{1 , 0 3 5}$ & 2,858 & 2,825 & 2,028 & 1,446 & 2,434 \\
\hline $\mathbf{1 8 8 0}$ & $\mathbf{1 , 2 5 5}$ & 4,090 & 4,866 & 2,812 & 2,118 & 3,276 \\
\hline $\mathbf{1 9 1 0}$ & $\mathbf{2 , 0 7 1}$ & 5,917 & 7,586 & 4,551 & 4,476 & 5,386 \\
\hline $\mathbf{1 9 4 0}$ & $\mathbf{3 , 7 3 2}$ & 9,264 & 11,307 & 5,131 & 6,206 & 5,283 \\
\hline $\mathbf{1 9 7 0}$ & $\mathbf{1 4 , 4 1 6}$ & 15,715 & 23,958 & 16,740 & 18,133 & 17,514 \\
\hline $\mathbf{2 0 0 0}$ & $\mathbf{3 2 , 9 7 2}$ & 34,390 & 45,887 & 31,771 & 36,374 & 39,923
\end{tabular}

Source: Maddison Project Database 2018

below two persons per square kilometer (Ojala et al. 2006), today the figure is around 18. Three quarters of the country's surface are covered with forests, constituting 23 million hectares of forest cover. This "green gold" has been by far Finland's most important natural resource for the last 500 years and even today forest industry products account for over $20 \%$ of the country's export revenues (Finnish Forest Industries Federation 2019). Other natural resources include mostly ores such as iron, sulfide, phosphate, and various other metals (Ojala et al. 2006).

The Finnish economy has experienced remarkable growth in the last 150 years the period for which accurate statistical data are available. In the early $19^{\text {th }}$ century, Finland was still a fully agrarian economy that was heavily regulated and reliant on foreign trade. As seen in Table 1, the Finnish economy was significantly behind most Western economies in 1820, mainly because it had not yet experienced the First Industrial Revolution. It finally started to slowly catch up during the interwar years, but even as late as the outbreak of the Second World War, the majority of the Finnish population was still employed in agriculture. It was only during the latter part of the $20^{\text {th }}$ century that Finland eventually became a highly versatile economy with both industries and services blossoming simultaneously. This progress was accompanied by the development of an extensive welfare state, high investments in education, and a considerable population shift from the countryside to the growing cities of southern Finland. Despite significant institutional, political, and economic changes such as the decline of the Soviet Union, deregulation of the financial markets, or the rise of ICT and globalization, Finland managed to accelerate the catching up process throughout the last decades (Ojala et al. 2006).

Similar and related to its tardy industrialization and economic progress, Finland can also be referred to as a latecomer in welfare state development. This is, however, only partly associated with its late industrial take-off and the comparably long persistence of a predominantly agrarian and rural social structure. In addition, the idea of a welfare state has been ideologically weaker in Finland than in most other Nordic countries due to particular features of the Finnish political history. Examples include the Civil War 
of 1918 resulting in a relative weakness of Social Democracy; the policy of refusing collective agreements with trade unions by Finnish employers; and the Agrarian Party being able to preserve a politically crucial role much longer that in most other European countries - all of these contributing to a delayed expansion of social security benefits and public services in Finland (Kettunen 2001). While there have been some improvements in the social security of Finns through various reforms in the late 1950s and early 1960s, the foundation of the present Finnish welfare state only began to be laid in the years after 1966, when political power was exercised mostly by left-wing and centered governments - a situation that continued until the mid-1980s. Today, Finland has one of the world's most comprehensive and advanced welfare systems. (Kujala \& Danielsbacka 2019).

While the prism of economic and political history can definitely provide some insights into Finland's remarkable road to prosperity, this paper focuses on the role of demography in explaining human development. Demographic data availability is exceptionally good in Finland. Figure 1 shows the annual crude birth rate (number of live births per 1,000 mid-year total population) and crude death rate (number of deaths per 1,000 mid-year total population) from 1722-2100 (including Wittgenstein Centre's projections according to the medium SSP2 scenario $^{1}$ ), reflecting the exceptionally longterm demographic data availability in Finland.

Figure 1: Crude birth rate and crude death rate, Finland, 1722-2100

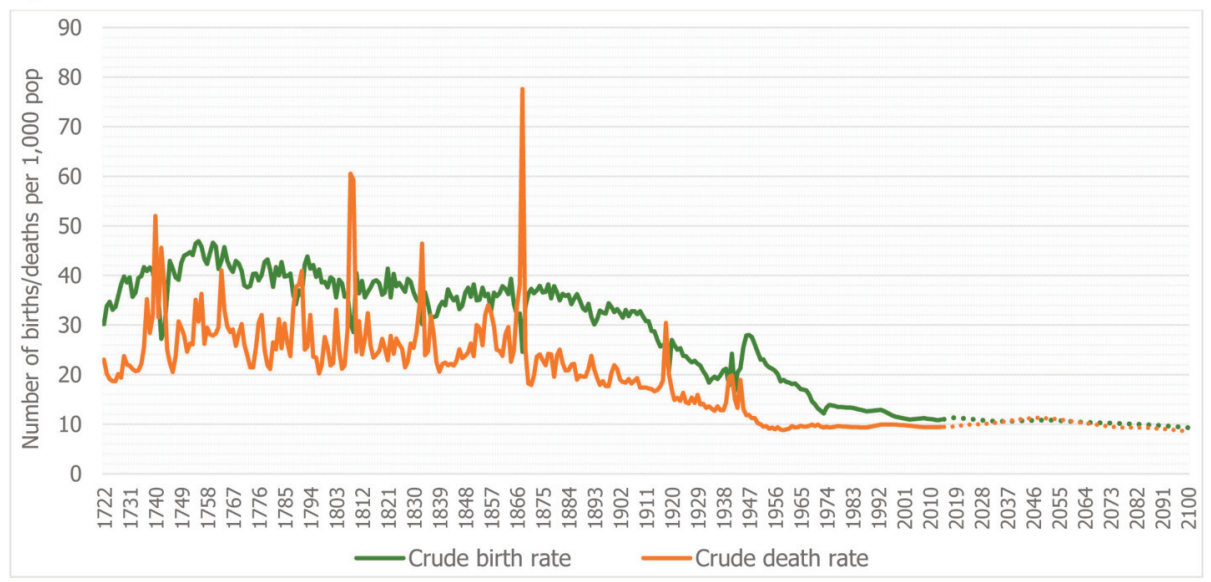

Sources: 1722-1980: Vattula 1983; 1980-2015: United Nations 2019; 2015-2100: Wittgenstein Centre 2018

1 The medium SSP2 scenario, which can also be seen as the most likely path, combines medium fertility with medium mortality, medium migration, and the Global Education Trend (GET) education scenario. For further details on the Shared Socioeconomic Pathways (SSPs) see O’Neill et al. 2017 and Riahi et al. 2017. Further features about the projection methodology can be found in Lutz, Butz, and K.C. (2014). 
This long-term depiction of the two drivers of natural population growth nicely demonstrates Finland's demographic transition over the past centuries. This shift from high birth and death rates to low birth and death rates as a country develops from a preindustrial to an industrialized economy usually involves a stage of rapidly dropping death rates (due to improvements in food supply and sanitation), followed by falling birth rates (due to lower desired family size, increases in the status and education of women, and other social changes) (Myrskylä, Kohler, \& Billari 2009). In Finland, mortality remained at a very high level with strong short-term fluctuations until the second half of the $19^{\text {th }}$ century. The sharp mortality peaks can be clearly related to catastrophic fatal events in Finnish history: the Russo-Swedish war from 1741-43, the Finnish war with the resulting annexation of Finland to the Russian Empire in 1808-09; back-toback harvest failures in the early 1830s; and finally, the last great famine catastrophe of 1867-68. After that, mortality entered a new phase of sustained decline, interrupted only by civil war and influenza in 1918 and wars with the Soviet Union in 1939-44. Around 1950, the decline suddenly accelerated due to the introduction of antibiotics and public health advances, and the crude death rate has been at a very low level ever since. Despite conditions of increasing life expectancy, a slight increase in the crude death rate can be observed at the end of the time series due to an older age structure of the population.

Regarding trends in the crude birth rate, there is an early modest decline from the mid- $18^{\text {th }}$ to the mid- $19^{\text {th }}$ century - even before the onset of the modern fertility transition. One possible explanation for this is provided by the hypothesis (Lutz 1987) that this reflects a transition to the so-called European Marriage System (Hajnal 1965), which is characterized by a high mean age at marriage and a high proportion remaining unmarried as opposed to the early and universal marriage pattern that was found in Eastern Europe. The modern fertility transition started only at the beginning of the $20^{\text {th }}$ century, with accelerated declines from 1910 to 1933. However, it was only after a strong and comparatively early baby boom (in 1945-50) that birth rates fell below replacement level. While cohort fertility in Finland has long remained relatively high and stable as compared to other European countries, in most recent years the total fertility rate declined significantly from 1.87 in 2010 to an all-time low of 1.41 children per woman in 2018 (Hellstrand, Nisén, \& Myrskylä 2019).

The graph on Figure 1 also clearly shows that Finland naturally grew in most of the past 300 years, demonstrated by crude birth rates mostly exceeding crude death rates. Only during catastrophic fatal events such as wars, famines, or epidemics, Finland experienced higher death than birth rates. For the future, Finland's population is projected to experience almost zero or even negative natural population growth, i.e. the country's population is expected to increase solely due to positive net-migration.

This long-term trend in population size is depicted in Figure 2, which shows the total population (in thousand persons) from 1750-2100. Before that, only estimates on population size are available suggesting that the total population in Finland in the late $16^{\text {th }}$ century was about 300,000 and grew to 450,000 by the end of the following cen- 
Figure 2: Total population, Finland, $1750-2100$

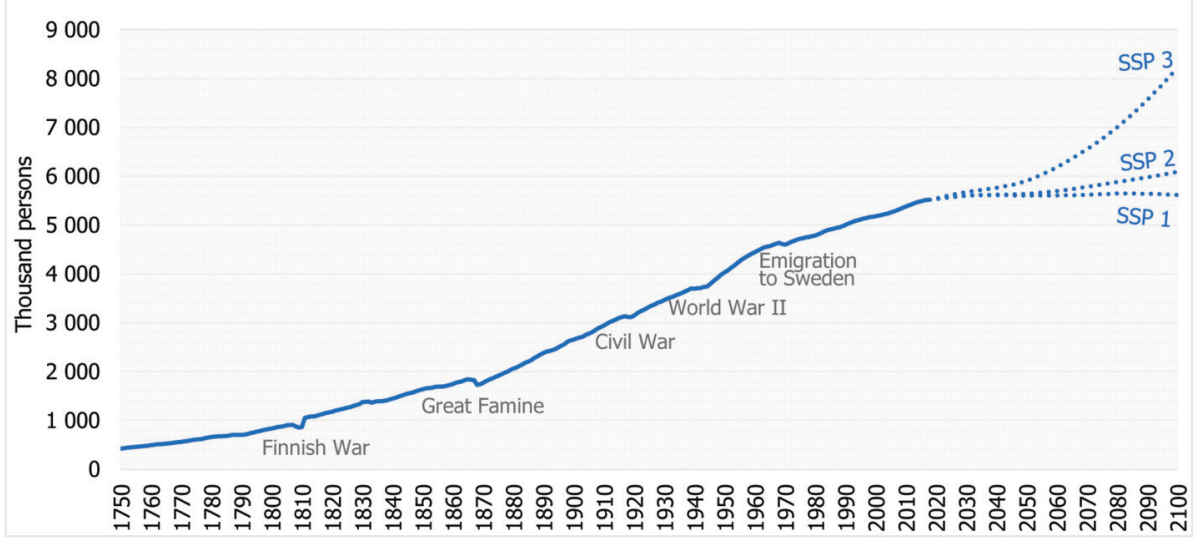

Sources: 1750-2018: OSF 2018; 2019-2100: Wittgenstein Centre 2018

tury. However, Finland lost around one third of its population during a catastrophic famine in the late $17^{\text {th }}$ century, and the prefamine population level was reached again only in the mid- $18^{\text {th }}$ century (Koskinen et al. 1994). From 1750 to 1950 the Finnish population roughly doubled every fifty years and grew from 422,000 in 1750 to $5,518,000$ in 2018 - an average annual rate of increase of $0.97 \%$. There are only a few troughs in the curve: first, in 1808 as a result of the annexation of Finland into the Russian Empire; second, in the late 1860s due to a devastating famine; third, in 1918 as a consequence of the Civil War; fourth, in the 1940s because of World War II; and last, at the turn of the 1970s as a result of emigration. As regards the future, Finland's population is - depending on the scenario choice of the predefined Shared Socioeconomic Pathways (SSPs) ${ }^{2}$ - projected to remain roughly constant (SSP1), slightly increase (SSP2), or considerably increase (SSP3), resulting in a projected total population between 5.6 and 8.2 million people by the end of the century.

2 Scenario definitions:

- Scenario SSP1 (Rapid Development): This scenario assumes a future that is moving toward a more sustainable path, with educational and health investments accelerating the demographic transition, leading to a relatively low world population. The emphasis is on strengthening human wellbeing. This is associated with high education, low mortality and low fertility. Migration levels are assumed to be medium for all countries under this SSP.

- Scenario SSP2 (Medium): This is the middle of the road scenario that can also be seen as the most likely path for each country. It combines for all countries medium fertility with medium mortality, medium migration, and the Global Education Trend (GET) education scenario.

- Scenario SSP3 (Stalled Development): This scenario portrays a world separated into regions characterized by extreme poverty, pockets of moderate wealth, and many countries struggling to maintain living standards for rapidly growing populations. This is associated with low education, high mortality and high fertility. Due to the emphasis on security and barriers to international exchange, migration is assumed to be low for all countries. 
However, not only the total number of population, but also the age structure within the population has significantly changed over time: in 1865, children below fourteen years of age constituted for more than a third of the population, whereas persons over the age of 65 only accounted for $4.6 \%$ of the population. In 2018, these figures were $16 \%$ and $21.8 \%$ respectively (Official Statistics of Finland 2019a). It is expected that population ageing will most likely continue in the future.

\section{Methodology \& data}

While the previous chapter aimed at providing some general background information on Finland, its economic and population history, and the country's demographic data availability, in the following sections the methodological foundations and data used for Years of Good Life in general (3.1) and for the reconstruction of YoGL in Finland (3.2) are explained. In addition, an overview of existing wellbeing indicators and how they differ from YoGL is provided.

\subsection{Years of Good Life (YoGL): An introduction}

When defining any indicator aiming at quantitatively measuring sustainable human wellbeing and assessing its progress over time, the main prerequisite is that it can stand alone on the left-hand side of a "wellbeing production function" as proposed by Clark (2012):

$$
W=f\left(C_{i}, I, K\right)
$$

where W stands for human wellbeing for different groups of people and at different points in time, $\mathrm{Ci}$ are 'Capital Assets' (from which services flow, in particular manufactured capital, human capital, and natural capital), I are institutions (laws, rules, norms, expectations, etc.) and $\mathrm{K}$ is knowledge (scientific, practical, innovation).

So far, research has mainly focused on studying the right-hand-side of this equation, i.e. production factors or determinants of wellbeing. Those existing indicators which actually aim at measuring $\mathrm{W}$ and its changes over time either only cover certain partial aspects of sustainable development or try to give weighted averages of a broad range of aspects, which typically can only be assessed for the past but not be modelled for the future. To overcome these shortcomings, Lutz et al. (2019) proposed a comprehensive indicator - so-called 'Years of Good Life' (YoGL) - with the explicit purpose of serving as an indicator of the ultimate end of sustainable development that can be assessed across countries, different subpopulations, and over time and be modelled as an outcome of the interplay of different "production factors", including feedbacks from environmental change on future human wellbeing. It is tailormade to meet the following six criteria: 
(1) It needs to embody universally shared values in terms of specific ultimate ends.

(2) It needs to be based on characteristics of individuals that can be flexibly aggregated to subpopulations.

(3) It needs to be comparable over time and across subpopulations.

(4) It should be theory based and not include implicit tradeoff assumptions or arbitrary weighting schemes.

(5) There needs to be sufficient empirical information for different subpopulations and time points to be fit for serving as the dependent variable in panel regressions.

(6) If possible, it should have a substantive interpretation in terms of some real-life analogy rather than just being an abstract index.

YoGL meets all of these six criteria. It is based on the fact that in order to be able to enjoy any quality of life, one has to be alive. But since mere survival is not considered as good enough, life years are counted conditional on meeting minimum standards in both objective and subjective dimensions. These dimensions are subject to a clear hierarchy: first and foremost, survival is considered as the most essential prerequisite for enjoying any wellbeing. In a next step, "good" years of life are defined as those years when people are above a minimum level both in terms of objectively observable conditions as well as subjective life satisfaction. Following Sen (Desai, Sen, \& Boltvinik 1992), the objective conditions measuring "capable longevity" are further broken down into three dimensions: being out of poverty, being cognitively enabled, and having no serious physical disabilities. Only if people are above critical levels in all three objective dimensions and in their self-reported overall life satisfaction, the life years are considered as good years in the calculation of YoGL.

Figure 3 summarizes this structure and basic logic of YoGL. The big grey circle cor-

Figure 3: Dimensions of Years of Good Life - a human wellbeing indicator

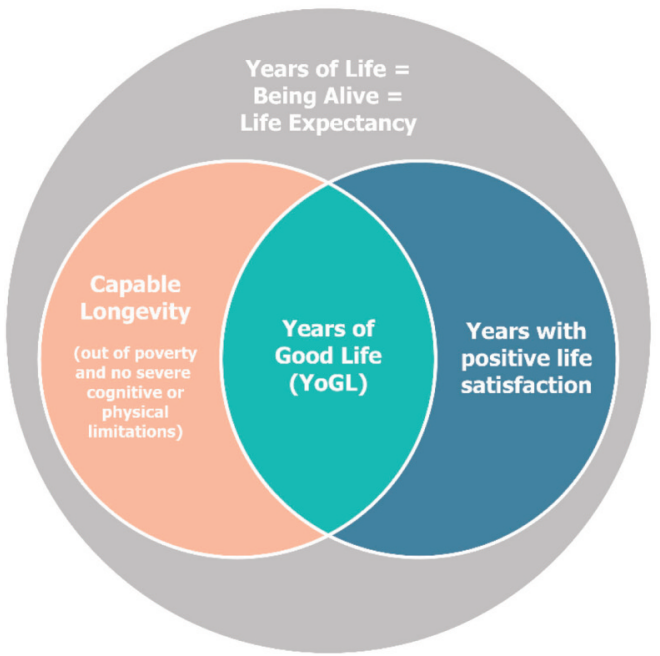

Source: Lutz et al. 2019 
responds to the overall years of life which summarize the life expectancy of a person based on the currently observed survival conditions in the chosen (sub)population. YoGL is a subset of these overall years of life depicted by the turquoise area indicating the intersection of capable years of life (orange circle, defined by three objective criteria) and years with subjective life satisfaction above a minimal level (blue area). More detailed information about the theoretical foundations, data requirements, and methods for calculating the indicator can be found in a forthcoming paper by Lutz et al. (2019).

\subsubsection{Overview of existing wellbeing indicators and comparison with YoGL ${ }^{3}$}

The field of wellbeing indicators is currently mushrooming. Over the past 50 years, a large number of institutions and researchers around the world have contributed to the development of human wellbeing indices, with the explicit aim of supporting governments in devising meaningful policy interventions and to spur the debate on how to best raise people's quality of life in different national and cultural contexts. For a comprehensive literature overview of existing wellbeing indicators see Ljadi (2018).

Up to the present, the by far most prominent and widely used wellbeing indicator continues to be GDP per capita. Yet, after heavy criticism of the concept (Stiglitz, Sen, $\&$ Fitoussi 2009), the majority of modern wellbeing indices look beyond the measurement of national income and pay more attention to social and ecological dimensions of human development, including social capital, governance, civil liberties, or environmental quality (Döpke et al. 2017; Menegaki \& Tugcu 2017; Michalos 2017). Many of the recently proposed indicators aim at one composite metric, which incorporates a multitude of these different dimensions. At least three possible strategies can be distinguished for composing: (1) one can leave the weighting of different aspects of the aggregate wellbeing indicator to the users, as is done e.g. by the OECD Better Life Index; (2) one can give fixed weights to the different dimensions, thus already implicitly making a choice about the trade-offs among components as exemplified by the UNDP Human Development Index (HDI) or the Social Progress Index; and (3) one can try to come up with a fully integrated indicator that can stand alone and has substantive meaning in its own right. The first approach, while being seemingly rather user-friendly, leads to non-comparable values depending on individual tastes and preferences. The second approach suffers from inconsistent trade-offs between sub-indices, as recently highlighted by Ghislandi et al. (2018). YoGL is based on the third approach as the most promising one to yield a wellbeing indicator that can also be used as sustainability criterion for different groups of people and is not constraint by national accounting frameworks.

3 This section is partly taken from Lutz et al. 2019. 
While several existing indicators acknowledge the multi-dimensional nature of human wellbeing, none of them meet all predefined six criteria for a fit-for purpose wellbeing indicator as highlighted above. For example, the Human Development Index (HDI), which is one of the most widely used indicators to measure human wellbeing, is only compatible with criterion $\# 5$, i.e. the index is fit for serving as the dependent variable in panel regressions. However, its dimensions include both means (e.g. years of education) and ends (e.g. survival), and is thus unsuitable for embodying universally shared values in terms of specific ultimate ends (criterion \#1). Criterion \#2 can also not be fulfilled, as the HDI includes GNI per capita, a dimension that only exists at national level and therefore cannot be flexibly aggregated to sub-populations. Moreover, it is not comparable over time (criterion \#3), since the life expectancy component of the HDI is defined as a fraction of the maximum national life expectancy observed in any given year. Finally, the index applies arbitrary weighting schemes (criterion \#4) and is reported as an abstract index without real-life analogy (criterion \#6).

Other existing wellbeing indicators perform better in terms of meeting our six criteria, with several fulfilling all but the first one, as they only consider one specific wellbeing dimension and thus do not capture the single most important ultimate end. Examples include Happy Life Expectancy (Veenhoven 1996), which includes besides survival solely the subjective well-being indicator of happiness, or Literate Life Expectancy (Lutz \& Goujon 2004), which uses self-declared literacy as indicator for the average number of years a person lives in the literate state. Other indices that employ life tables are heavily focused on health and health outcomes, e.g. Quality-adjusted Life Years (QALY) (Weinstein, Torrance, \& McGuire 2009), calculated by estimating the years of life remaining for a person following a particular treatment or intervention and weighting each year with a quality-of-life score; Disability-adjusted Life Years (DALY) (Murray \& Lopez 1994), which can be thought of as one lost year of "healthy" life; and Disability-free Life Expectancy (DFLE) (Crimmins, Saito, \& Ingegneri 1997), which is the average number of years a person is expected to live free from disability. A comprehensive review of how existing wellbeing indicators differ from YoGL and whether they are compatible with our six criteria can be found in the forthcoming paper of Lutz et al. (2019).

\subsection{Reconstruction of YoGL in Finland}

The following section provides a full account of which data and indicators were used in estimates for the reconstruction of YoGL in Finland. Applied methods and underlying assumptions are described in detail for each of the YoGL dimensions. 
Figure 4: Life expectancy at birth, Finland, 1751-2015

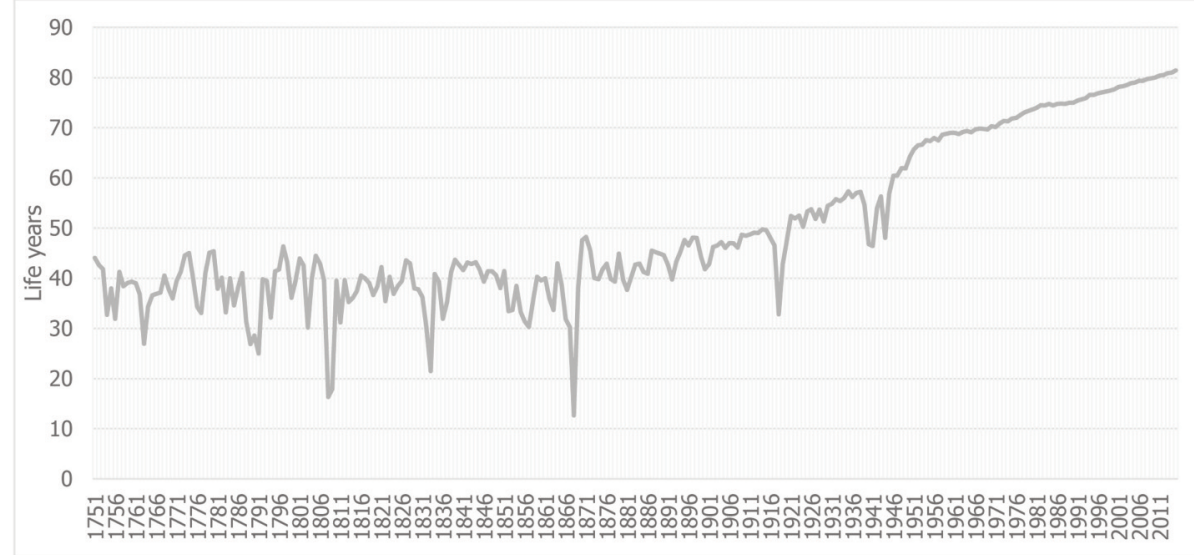

Sources: 1751-1877: Turpeinen 1979; 1878-2015: Human Mortality Database 2017

\subsubsection{Life expectancy}

Life expectancy - a statistical measure of the average time an organism is expected to live under currently observed age-specific mortality rates - is a widely used demographic indicator. In the case of Finland, such age-specific mortality rates are available from 1751. For this case study, annual mortality data for 1751-1877 come from Turpeinen (1979). Based on standard life table techniques, age-specific mortality rates were converted into age-specific survival probabilities and by using a multiplicative combination of these probabilities, average durations of remaining life at different ages were derived. Starting from 1878 full period life tables provided by the Human Mortality Database (HMD) (2017) are available and are used from 1878-2015.

Figure 4 shows the life expectancy at birth for Finland from 1751 to 2015. Life expectancy considerably increased and almost doubled within the period of observation. However, after significant fluctuations during the $18^{\text {th }}, 19^{\text {th }}$, and first half of the $20^{\text {th }}$ century, reflecting major catastrophic events including wars, famines, and epidemics in Finland, life expectancy only started steadily increasing after World War II, with largest increments during recent decades. Today, Finland ranks 26 in terms of life expectancy at birth in global comparison (United Nations Population Division 2019).

\subsubsection{Capable longevity}

Given the clear distinction between subjective and objective dimensions of good life within the framework of YoGL, capable longevity should ideally be measured through objectively observed characteristics (Lutz et al. 2019). However, for such long-term historical time series, this kind of data is naturally not available. Therefore, proxy indicators and estimates have to be used to derive adequate assumptions about living conditions in historical Finland. As it seems likely that the different indicators are highly 
correlated with each other, inferences are also drawn between the different YoGL dimensions. In the following, the methodology and data used to estimate each of the three dimensions of capable longevity are explained.

\section{Being out of poverty.}

Poverty can be understood in absolute or relative terms. While absolute poverty is concerned with the deprivation of basic human needs, such as nutrition and shelter, relative poverty is concerned with the distribution of resources within society. It compares different segments of the population with one another, for example the lowest and the highest quintiles of the income distribution. In contrast to absolute poverty, relative poverty is not determined in relation to a fixed standard of living (Lok-Dessallien 2000). Following Desai et al. (1992), who identified basic material subsistence as one of three "basic capabilities" that jointly determine a person's "freedom" to achieve wellbeing (besides basic health and cognitive functioning), we are interested in measures of absolute extreme poverty within the context of the YoGL capable longevity dimension.

While today's measures of poverty rates rely on household surveys that record the level of income or consumption of a representative sample of households, a different approach is needed to study the prevalence of poverty in historical periods. One research focus has been traditionally on the history of poor relief, its characteristics and changing policies. In Finland, poor relief historically was a locally funded system based on the Lutheran parish structure. The Poor Relief Act of 1852 established compulsory local boards and accompanying taxation for relief and made it possible to obtain temporary relief. As documented in poor relief figures in official population statistics, recipients in Finland were a rather heterogeneous group including children in need of protection, the insane, the disabled, and the elderly (Voutilainen 2016).

While these statistics are certainly interesting to better understand the historical context, they may be too narrow to accurately describe poverty. Frigren, Hemminki, \& Nummela (2017), for example, argued that any "temporal and spatial variations have to be read here with extreme caution" (p.12), mainly because reasons for changes of the growing burden of poor relief are not necessarily a changing number of needy people, but could be very diverse (e.g. changing legislation in terms of eligibility, changing amount of poor relief money, incomplete statistics, etc.). A telling example for this is the clear jump in number of poor aid recipients between 1850 and 1855. Contemporary literature argues that the increase is highly unlikely to result from macroeconomic problems, but is rather due to the poor relief reform per se (i.e. allowance for temporary relief). Consequently, when taking poor relief statistics as an estimate for poverty rates, any changing structure of the poor relief system may considerably distort the results.

Another approach to study the prevalence of poverty in historical periods is to rely on the 'national accounts' method, in which poverty estimates are derived from economic historians' reconstructions of historical prosperity and inequality (Hasell \& Roser 2019). In a recent paper by Roikonen and Heikkinen (2018) income inequality in Fin- 
land for the years 1865-1934 was estimated based on Finnish tax statistics. This case study takes use of the underlying estimated income distribution of Finland in the $19^{\text {th }}$ and $20^{\text {th }}$ century reconstructed within the framework of the above-mentioned paper. While there are definitely some shortcomings involved when using tax data to study poverty - most obviously the lack of information about incomes of nontaxed households - these issues can partly be resolved by the authors' decision to include relevant complementary data, such as a survey to five rural municipalities in 1903 as well as senior tax official's estimates for nontaxed households in 1880. Although the slight heterogeneity of the data causes some problems, we believe that these estimates of income distributions are sufficiently valid to serve as basis for reconstructing historical poverty rates in Finland. A detailed description of the methodology and data sources used can be found in Roikonen \& Heikkinen, 2018.

In addition to valid information about distributions of income over time, a credible measure of poverty also requires setting a plausible poverty line, defined as the minimum level of income required to maintain basic living standards. For reconstructing poverty in Finland to estimate capable longevity, we decided to use needs-based poverty lines, focusing on indigence and basic human needs. For this purpose, most commonly used is the cost of basic needs approach. It first estimates the cost of acquiring enough food for adequate nutrition and then adds on the cost of other essentials such as clothing and shelter (Ravallion 2008). In this case study, foodstuff and other consumer prices as documented in Vattula (1983) are used. In order to allow for changes in prices and take account of inflation, we used the annual cost-of-living index estimated by Heikkinen, which provides detailed register of the development of different consumer good prices including a wide range of food, beverages, clothing, rents, heating and lighting as well as basic kitchen utensils, all considered to be essential to maintain basic living $\operatorname{standards}^{4}$ (Heikkinen 1997).

For those years where no reliable data on income distributions and costs of living are available, we estimated the poverty rates based on long-term trends of poor relief statistics (National Library of Finland 2018) and average private consumption expenditure (Hjerppe 1989; OSF 2019). ${ }^{5}$ This allowed us to reconstruct the population being

4 Since no detailed price information for all consumer goods which are considered to be essential to maintain basic living standards is available, prices are partly estimated by using group indices (e.g. food, clothing, rents, etc.) and subgroup indices (e.g. cereals, bread, etc.) as calculated by Heikkinen (1997). These indices provide information about the distribution of consumer expenditure to satisfy basic human needs within and between consumer good groups.

5 Poverty rates for the years 1860-1864 and from 1935 onwards were calculated analogous to the average of annual development of poor relief statistics (National Library of Finland 2018) and changes in average private consumption expenditures (Hjerppe 1989 \& OSF 2019). The average of these two variables was used (rather than using only trends in the number of poor relief recipients) to minimize potential distortions due to the changing structure of the poor relief system. Most recent years (2002-2015) were additionally adjusted to poverty rates published in the World Development Indicators (World Bank 2017). 
Figure 5: Estimated share of population being out of poverty, Finland, 1860-2015

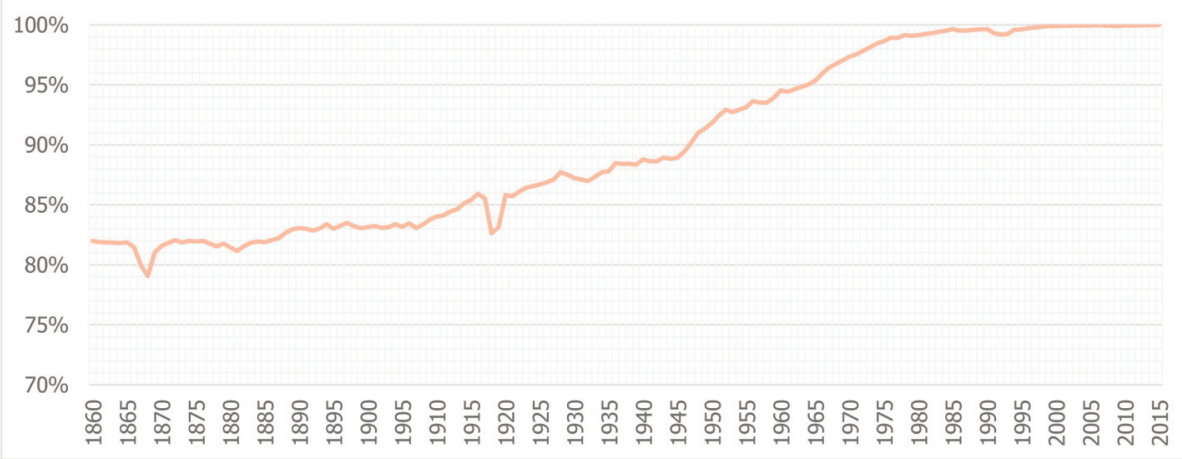

Source: Authors' calculations

out of absolute extreme poverty over more than one and a half century from 1860-2015 as shown in Figure 5. The graph clearly depicts a considerable upward trend. While in the 1860s almost every fifth Finn had less than the minimum level of income which would be required to maintain basic living standards at her disposal, in today's Finland basically everyone lives out of poverty - which bears witness to the generous social welfare system that evolved in Finland over the last few decades. Nevertheless, poverty rates were considerably fluctuating over time, most notably during the great Finnish famine of 1868-69 and the 1918 Finnish Civil War.

When analyzing these results, it is important to highlight that estimates of extreme poverty are never exact, as the poorest people usually face unpredictable and constantly changing living conditions with few documented monetary transactions. This is problematic today, but the problem is even larger for historical estimates. Also, the very application of modern conceptions of poverty in historical instances has aroused considerable debate. Estimates of the extent of the pre-industrial Finnish poverty vary greatly for different measures - all of these involving different, but similarly critical shortcomings. While income tax registers fail to include the lowest end of the income distribution and tax exemptions may be distorted by obscurities in regional practices and loopholes in the legislation, local poor relief registers are too inclusive and include only the most clear-cut cases of poverty, whereas the usage of contemporary social groups disregards intra-class variation in economic conditions (Voutilainen 2016). Although some critical dilemmas certainly also persist in the methods presented above, it is reasonable to argue that these results do have relevance in the assessment of a longterm trend of capable longevity in Finland.

\section{Having no severe activity limitation.}

Estimating the proportion of the population who have no difficulties in activities of daily living is particularly challenging for a long-run historical time series. While there 
are some historical data on health indicators available (e.g. mean human height by Baten \& Blum 2015, number of hospitals, or population per medical doctor by Saarivirta, Consoli, \& Dhondt 2012), which all might reveal some information about the health situation in historical Finland, it is difficult to infer from such average values to the proportion of population who actually suffered from severe activity limitations.

In order to more accurately estimate the share of those who were severely limited in their daily activities over more than a century, we take advantage of the correlation between those living in poverty and those with severe health impairments. This positive relation between income and health is one of the best established in international development, particularly for developing countries (see for example Bloom \& Canning 2000; Fuchs 2004, etc.). For this case study, we build our correlation-based estimates on already calculated YoGLs for 38 countries at very different development stages all over the world, where data availability in all dimensions is excellent in terms of YoGLspecific requirements and criteria. Reference countries for Finland for each year of the observation period are selected based on their similarities in life expectancy, which is regarded as a proxy of the general development stage of the country. ${ }^{6}$ In a next step, individual-based correlation between poverty prevalence and prevalence of physical limitations are used and adjusted to the respective age- and sex-specific distribution of the Finnish population at each point of time to derive the share of population without severe activity limitation in Finland from 1860-2015. To avoid statistical outliers, results were smoothed using moving average smoothing techniques.

Figure 6 depicts the resulting estimated share of the population having no severe activity limitations in Finland from 1860 to 2015 . As compared to poverty and life expectancy, this dimension is characterized by less fluctuations and lower general prevalence. This can be explained by the fact that in every population - regardless how wealthy, developed and advanced the nation is - there is always a certain proportion of people with physical disabilities or severe physical impairments. Nevertheless, the overall development over time can clearly be evaluated positively, with the share of physically unlimited people significantly increasing over time. The recent minor decrease noticeable on the graph is due to recent changes in Finland's age structure, i.e. a higher share of elderly people experiencing disproportionately higher rates of health problems.

6 Countries with lower life expectancy, which are consequently used as reference country in earlier years of the observation period, include e.g. Zimbabwe; highly developed countries with similar life expectancy as in nowadays Finland include e.g. the Netherlands or Sweden. A complete list of countries with available YoGL calculations as well as a detailed description of methods and data used for each dimension can be found in Lutz et al. 2019. 


\section{Being cognitively able in terms of basic numeracy and literacy.}

Even though there exist no long-term historical data on tested cognitive health and performance of the Finnish population, Finland has a remarkably long tradition in collecting literacy data. Statistical Yearbooks provide information about the share of population who were partly literate (can only read) or fully literate (can both read and write) for the years 1880-1910. Before that, despite the lack of comprehensive nationwide statistics about reading and writing, there are several estimates based on local and regional studies (e.g. Myllyntaus 1990) as well as detailed church records. These records are a consequence of the promulgation of the Swedish Church Law of 1686, which declared it to be a duty of every citizen to learn to read and additionally learn by heart a considerable number of religious texts. As reading of the catechism was also made a precondition for being able to marry, act as a godparent, and attend the Eucharist, examinations of literacy skills by local priests took place on a regular basis in Finland (Laine \& Salmi-Niklander 2018).

Figure 7: Estimated proportion of literate population (15+), Finland, 1740-1920

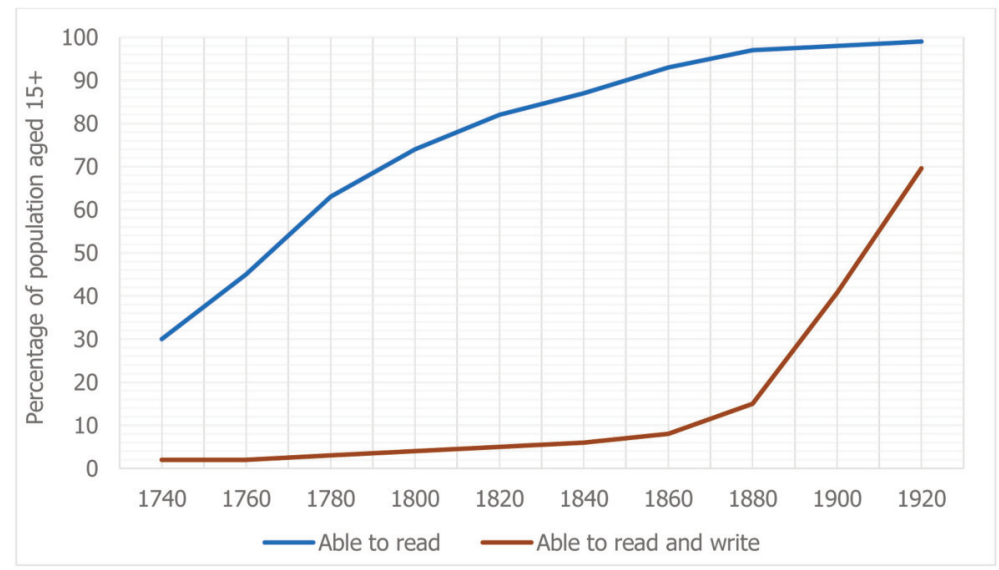

Source: Myllyntaus 1990

Figure 7 summarizes the estimated proportion of the literate Finnish population (15+) for the years 1740-1920 based on above described data and records. When considering these estimates, some paradoxical and contradictory features arise. On the one hand, Finland introduced compulsory school attendance only in 1921 as one of the latest countries in Western Europe. At the beginning of the $20^{\text {th }}$ century, the proportion of fully literate persons was lower in Finland than in most other European countries. On the other hand, in respect to the ability to read, this agrarian periphery was clearly ahead of various major contemporary European economies with developed industry and long cultural traditions, such as England and France. As early as 1800, over $70 \%$ of the Finns older than 15 years were estimated to be able to read and fifty years later, this percentage has further risen to about $90 \%$ (Myllyntaus 1990). 
While these data are certainly interesting to better understand the historical context, they imply a nonnegligible shortcoming for their application in reconstructing YoGL: the ability to read and/or write in such an undeveloped country as Finland was in the past is clearly much more associated with the opportunity to learn rather than the cognitive ability to do so. Since within the framework of YoGL, as specified earlier, cognitive ability is considered as one of the constituents of wellbeing, whereas education is defined as determinant and is thus part of the production function of wellbeing, alternative measures to estimate the historical share of the population with basic cognitive ability need to be applied.

Similarly to the dimension of physical limitations, we decided to make use of correlations between the prevalence of poverty and the prevalence of cognitive ability. This relationship was analyzed and acknowledged numerous times in the literature (e.g. Mani et al. 2013; Magnuson 2012, etc.) and is thus based on strong scientific groundings. Our methodology follows the same steps as described in the previous section. The graph on Figure 8 depicts the estimated share of population being cognitively able in terms of basic numeracy and literacy in Finland from 1860-2015. Again, there is a minor decrease observable in most recent years, reflecting Finland's increasing number of elderly people with higher impairments which leads to a fractionally increasing share of cognitive impairment among the total population.

Figure 8: Estimated share of population being cognitively able in terms of basic numeracy and literacy, Finland, $1860-2015$

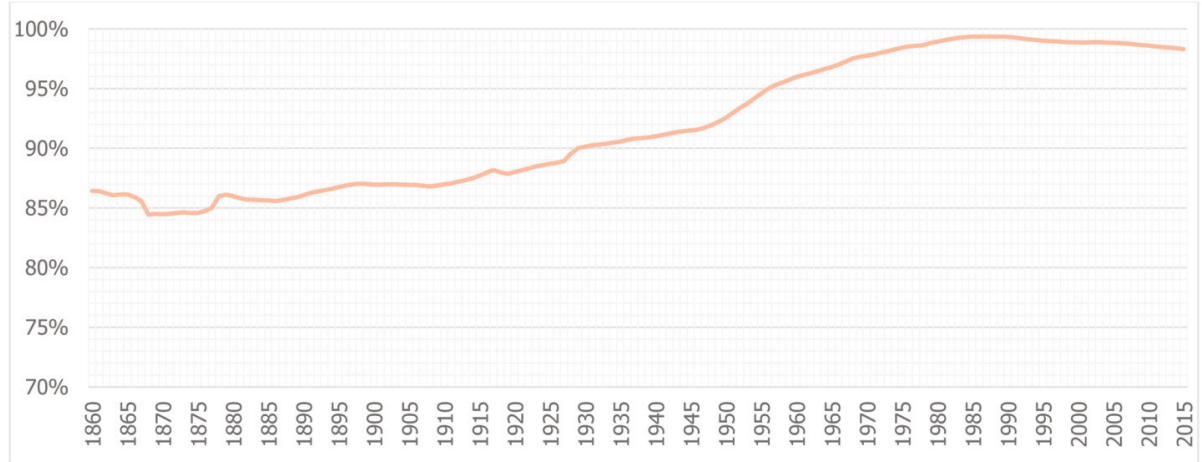

Source: Authors' calculations

\subsubsection{Overall life satisfaction}

After reconstructing both life expectancy and capable longevity, the final step in the reconstruction of YoGL requires an estimation of the subjective dimension of wellbeing. While today Finland can pride itself on being the happiest country of the world according to the World Happiness Report (Helliwell, Layard, \& Sachs 2019), estimating historical life satisfaction for the Finnish population is without doubt the most challenging 
Figure 9: Crude marriage rates, Finland, 1722-1984

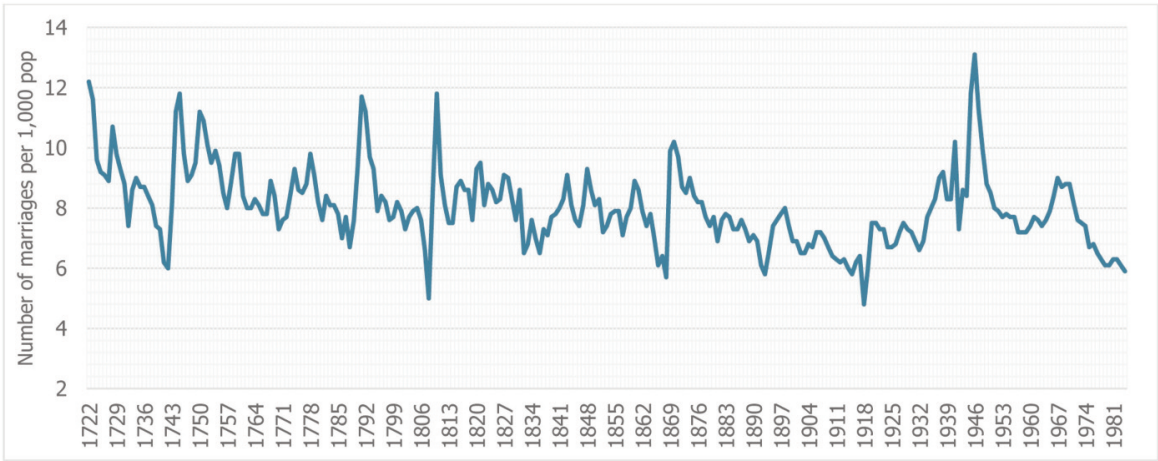

Sources: 1722-1965: Strömmer 1969; 1966-1984: Statistical Yearbook of Finland

part of the historical reconstruction of YoGL. As surveys measuring life satisfaction were first introduced in Finland only in the 1980s, potential proxy indicators which are likely to correlate with self-declared life satisfaction were considered for a first approximation. A number of indicators were taken into consideration, including marriage rates, consumption of alcohol, homicide rates, and criminal statistics.

Based on literature suggesting a particularly significant positive relationship between marriage status and quality of life/happiness (e.g. Lawrence 2018; Carr et al. 2014, etc.) and due to the good longitudinal data availability, marriage rates were believed to be a particularly adequate proxy indicator to estimate long-term life satisfaction in historical Finland. Figure 9 depicts annual crude marriage rates, i.e. the number of marriages by 1,000 population, from 1722 to 1984 . As can be seen on the graph, marriages in Finland were strongly fluctuating, with no definite trend over time. After conducting some sensitivity analyses and consulting the relevant literature, the use of the crude marriage rate as a proxy for life satisfaction, however, turned out to be problematic for two main reasons: (1) While there is empirical evidence that people's marriage status has an impact on their life satisfaction, it is not so clear whether this impact holds when only considering the share of population who is below a certain threshold of self-declared life satisfaction. As crude marriage rates only reflect the ratio of the number of marriages to the average population in a given period of time and do not reveal any information about the distributional aspects of the (assumingly) correlated life satisfaction, strong assumptions would have to be made to meet the requirements to calculate YoGL. (2) Even if the distributional function of subjective life satisfaction could be estimated, we would still face the difficulty of disentangling the (assumed) underlying life satisfaction trend from other influencing factors, such as economic and cultural aspects as well as changing norms and values.

Therefore, we decided to base our estimates first on recent empirical data and second on correlations of reference countries meeting the YoGL-specific data criteria. Empirical data is available from the European Value Survey $(1990,2000,2009,2017)$, the 
Figure 10: Share of population with positive life satisfaction, Finland, 1860-2015

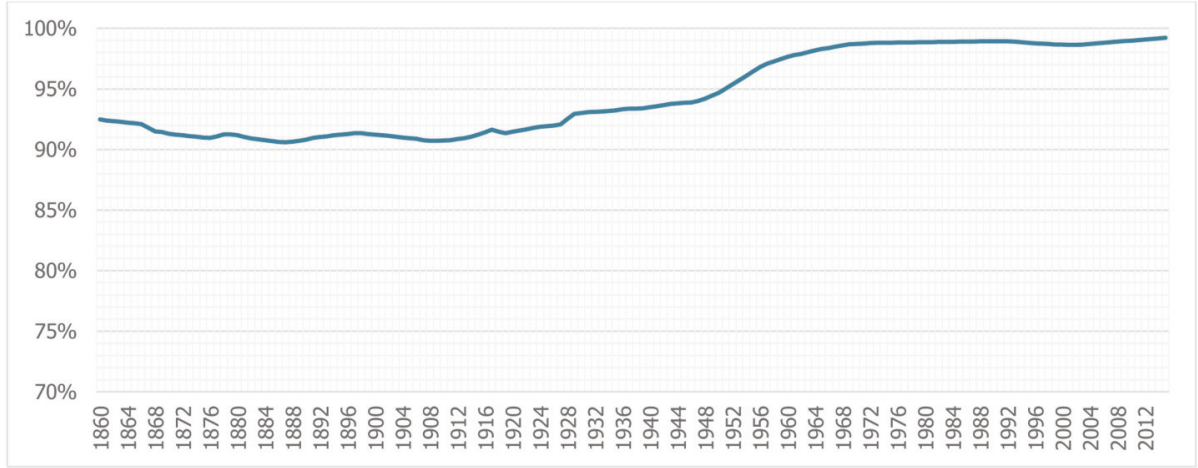

Source: Authors'calculations

World Value Survey $(1996,2005)$ and the statistics on living conditions by Statistics Finland (1996-2018). Earlier estimates are based on the same methodology as for the reconstruction of the share of population with no severe activity limitations and the share of population with basic cognitive ability (see Section 3.2.2).

Figure 10 presents the share of the Finnish population with positive life satisfaction from 1860-2015. As compared to capable longevity, overall life satisfaction in Finland was exposed to much less variation throughout the past centuries. The share of population above a minimum threshold of life satisfaction basically stayed more or less constant from 1860 to 1950 and only increased slightly thereafter. The most recent noticeable minor improvement is in line with the latest Global Happiness Report, which ranked Finland in first place for the second year in a row (Helliwell et al. 2019).

\section{Application \& results}

Once all dimensions are estimated accordingly, the final step for the reconstruction of long-term wellbeing in Finland involves the actual calculation of YoGL. This calculation is based on observed prevalence life table methods (Sullivan method) in which age-specific person-years lived are multiplied by age-specific proportions of the population who are above a critical level in all YoGL dimensions. Consequently, a year is only counted as a good year for those people that are above the critical thresholds in both capable longevity and subjective overall life satisfaction. The total expected years of good life will then be obtained by summing up the age-specific person-years of good life for all remaining age groups above the age at which remaining life expectancy shall be assessed (Lutz et al. 2019). The formula below summarizes the calculation in mathematical notation

$$
\frac{1}{l_{0}} \sum_{i=0}^{A} \pi_{i} L_{i}
$$


where $l_{0}$ denotes the number of survivors at age $X_{\mathrm{i}}$ (beginning of the interval $i$ ); $L_{\mathrm{i}}$ indicates the number of person-years lived in the age group $i$, and $\Pi_{\mathrm{i}}$ denotes the prevalence of the state of interest.

As with total life expectancy, YoGL can be assessed at birth as well as at any other age considered appropriate. However, since the lack of good quality long-term data only allowed us to estimate the prevalence of the different wellbeing dimensions within the total population but no age- and sex-specific patterns, the percentage of population that are above the critical thresholds in both capable longevity and subjective overall life satisfaction were kept constant among all age groups and for both males and females.

Unfortunately, data used for the reconstruction of the Finnish YoGL back to 1860 do not meet all conditions required to calculate the wellbeing indicator in an ideal way (as described in 3.1) - mainly due to limited data availability as required statistics and surveys were simply not conducted and available back then. Therefore, estimated results need to be handled with utmost care. Nevertheless, we are confident that the availability of long historical demographic time series combined with good social and economic data allowed us to cover the full life cycle of many individual cohorts with respect to pertinent characteristics relevant for measuring wellbeing.

Figure 11 presents the complete reconstruction of Years of Good Life at birth in Finland from 1860 to 2015 as compared to life expectancy at birth for the same time period. The graph shows that wellbeing as measured in Years of Good Life has significantly increased over the observation period. While in 1860 the average Finnish new-born could expect to live only roughly half of her expected life years as good years (20.5 years out of a total life expectancy of 39.6 years), this proportion has increased to more than 90 percent in 2015, when 73.7 years out of 81.4 expected life years are on average regarded as good years. Similar to life expectancy, a steady increase of YoGL only happened in the second half of the $20^{\text {th }}$ century - before that YoGL was marked by considerable up and downs, even though the upward trend was clearly prevailing. The most

Figure 11: YoGL and life expectancy at birth, Finland, 1860-2015

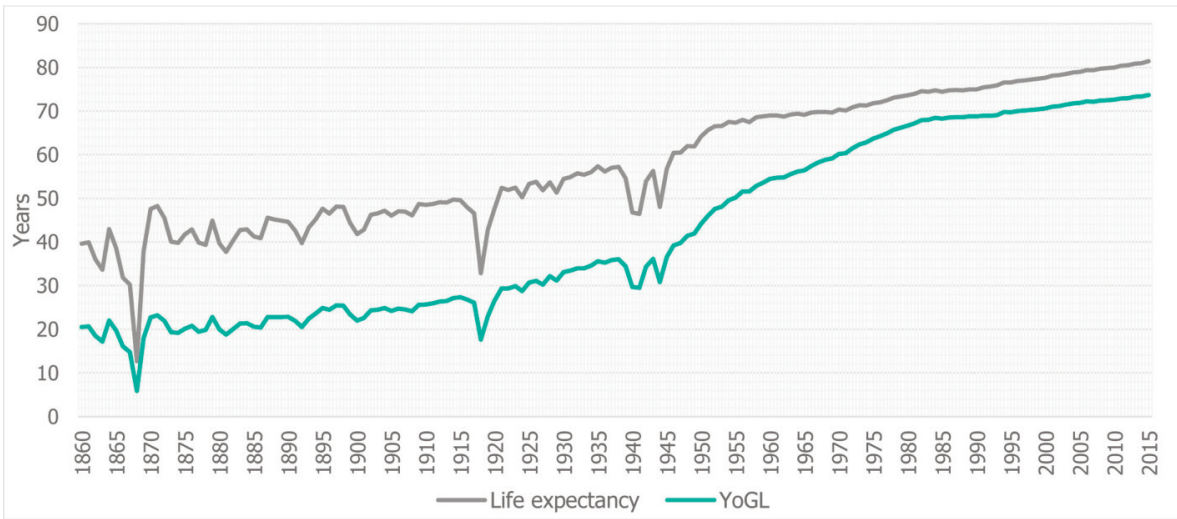


rapid increase in wellbeing happened in the four decades between the years 1944 and 1984, where YoGL more than doubled from 30.9 years to 68.8 years.

When comparing the years of life with the good years of life, it becomes clear that life expectancy was exposed to much stronger fluctuations over time (i.e. fatal events such as wars, famines, and epidemics). YoGL was certainly also affected by catastrophic historical events, but clearly not to the same extent as life expectancy. Further, the two lines slowly converge over time, indicating that the proportion of life a Finnish person can expect to live in wellbeing is much larger today than it was 150 years ago.

When trying to interpret these results, it is important to remember that the figures demonstrated here cover the total Finnish population, whereas YoGL has been initially designed to be potentially applicable to any subpopulation. Unfortunately, current data availability only allows an analysis on the aggregate level, but one should bear in mind that results may significantly differ among men and women, different age groups, urban and rural population as well as by highest level of educational attainment.

\section{Discussion \& outlook}

In this paper we analyze Finland's development success story over the centuries through the lenses of YoGL, a newly introduced indicator for human wellbeing that has been specifically designed to serve as a criterion variable for judging whether long-term development trajectories can be considered as sustainable or not. This indicator first builds on the fact that in order to be able to enjoy any quality of life, one has to be alive. But since mere survival is not considered as good enough, life years are counted as "good" only if minimum standards in both objective dimensions of capable longevity and in the subjective dimension of life satisfaction are met.

Finland has done remarkably well on both objective and subjective aspects of this indicator. As was shown, substantial improvements were not only achieved in life expectancy, but also in capable longevity and general life satisfaction among the Finnish population. Despite the long-term trend in all of these dimensions being clearly positive - for subjective wellbeing this is only based on indirect estimations - it was, however, only during the last few decades that Finland really forged ahead and is now among the most advanced countries in the world - not only in terms of economic indicators, but particularly as regards length of life and quality of life in a more holistic perspective.

The results of the historical reconstruction and estimation of YoGL presented here already allows to draw some descriptive conclusions about Finland's development and is thus an important first step in in trying to understand the drivers of and reasons for this success. As mentioned in the introduction, this definition of the dependent variable, i.e. the indicator of success that shall be explained, is a necessary first step to be followed by further steps which will try to identify the main determinants and their relative contributions. Only when doing a long-term systems analysis on population-develop- 
ment-environment interactions including important feedbacks, we can hope to fully understand and quantitatively model how one of the poorest corners of Europe in the mid$19^{\text {th }}$ century became one of the most developed with very high levels of human wellbeing today.

Based on the analysis of the drivers of human development in other countries (Lutz 2017, Lutz \& Klingholz 2017) and studies of the specific Finnish case (see for example Laine et al. 2019; Kokkinen 2012), we already have the hypothesis that Finland's remarkable development is first and foremost a consequence of its strong emphasis on investing in human capabilities and the cognitive development of broad segments of the population. Kokkinen (2012) has already shown that the considerable input in education has a significant relation with the dramatically changed economic performance in Finland in the $20^{\text {th }}$ century - with this relation becoming stronger with more advanced stages of development. We expect the drivers of human capital being similarly strong when looking at Finland's overall human wellbeing. Finland is well known for its highquality education, ranging from unique early childhood development programs (Neuvola) to a good and egalitarian school system (illustrated by Finnish students regularly being among the top performers in international standardized student assessments), and strong efforts in promoting lifelong learning and adult education. This was initiated mainly in the 1970 s and -80 s - a decade that can be regarded as the "golden era" of the Finnish welfare state, associated with social progress that is also reflected in our YoGL results. With Finland being - compared to other European countries - a latecomer in welfare state development, important reforms and investments mainly took place during this period. Particularly important in this regard was the termination of the division of the educational system into secondary schools for higher education and elementary schools for farmers and workers, with the latter being stripped of "unnecessary" subjects - a system which was finally discontinued and replaced by comprehensive schooling for all young people of compulsory education age in the late 70s (Kujala \& Danielsbacka 2019). The historical roots of the strong emphasis on cognitive development and human capabilities in a country with little other resources than human minds seem to go, however, already back to the second half of the $19^{\text {th }}$ century, when after the shock of the great famine years of 1867-68 universal public education received a great push, with the number of primary school teachers increasing by a factor of ten over less than 30 years (Lutz 1987). Nevertheless, it took Finland several decades more until it introduced compulsory schooling in 1921 as one of the latest countries in Western Europe (Myllyntaus 1990).

The further elaboration and testing of our hypothesis as well as the analysis of the environmental sustainability of current trends need to be subject of further studies. This is indeed a daunting research agenda. However, since it addresses some of the most important questions of our time - both for Finland and the rest of the world - it is worth great efforts. Hopefully, this estimation of a wellbeing indicator as the dependent variable turns out to be a useful first step. 


\section{Acknowledgments}

We are very grateful to Sakari Heikkinen and Petri Roikonen, whose support and obliging provision of data greatly improved this work. Furthermore, we want to thank Mirkka Danielsbacka, Anna Dimitrova, Tuija Laine, Ilona Pikkanen, Anna Rotkirch, Sonja Spitzer, Erich Striessnig, Dilek Yildiz, and all participants of the 2nd Uusikuapunki Peace Symposium for their valuable input and comments.

This work received funding from the European Research Council (ERC) under the European Union's Horizon 2020 Research and Innovation programme (Grant Agreement No. 741105 "The demography of sustainable human wellbeing”). The funders had no role in the design and execution of the study; in the collection, analysis, and interpretation of the data; or in the preparation, review, and approval of the manuscript.

A first version of this paper was presented at the international Uusikaupunki Peace Symposium on 8-9 August 2019.

\section{References}

Baten, J., \& Blum, M. (2015). Height. Retrieved from Clio Infra Website: http://hdl.handle.net/10622/IAEKLA

Bloom, D. E., \& Canning, D. (2000). The health and wealth of nations. Science 287(5456), 1,2079. https://doi.org/10.1126/science.287.5456.1207

Central Intelligence Agency. (2019). The World Factbook: Finland. Retrieved August 14, 2019 from CIA Website: https:/www.cia.gov/library/publications/the-world-factbook/geos/fi.html

Clark, W. C. (2012). Sustainability science: Its origins, evolution and challenges. Retrieved August 13, 2019 from IIASA Website: http://conference2012.iiasa.ac.at/person.html? $\operatorname{code}=$ clark\&scode $=s 2 \mathrm{~s} 7$

Crimmins, E. M., Saito, Y., Ingegneri, D. (1997). Trends in Disability-Free Life Expectancy in the United States, 1970-90. Population Development Review 23, 555-572. https://doi.org/10.2307/2137572

Desai, M., Sen, A., \& Boltvinik, J. (1992). Social Progress Index: A Proposal. Bogotá: United Nations Development Programme.

Döpke, J., Knabe, A., Lang, C., \& Maschke, P. (2017). Multidimensional well-being and regional disparities in Europe. Journal of Common Market Studies 55(5), 1026-1044. https://doi.org/10.1111/jcms.12551

Eurostat. (2019). Area by NUTS 3 region. Retrieved August 20, 2019 from EUROSTAT Data Explorer Website: https://appsso.eurostat.ec.europa.eu/nui/show.do?dataset=reg_area3\&lang=en

Eurostat. (2019). Population on 1st January. Retrieved August 20, 2019 from EUROSTAT Data Explorer Website:

https://ec.europa.eu/eurostat/tgm/table.do?tab=table $\&$ plugin $=1 \&$ language $=$ en $\&$ pcode $=\operatorname{tps} 0000$ 1

Finnish Forest Industries Federation. (2019). Statistics: Forest Industry. Retrieved August 16, 2019 from FFIF Website: https://www.forestindustries.fi/statistics/forest-industry/

Frigren, P., Hemminki, T., \& Nummela, I. (2017). Experiencing and Encountering Impoverishment in Nineteenth-Century Finland. Journal of Finnish Studies, 20 (1), 5-37.

Fuchs, V. R. (2004). Reflections on the socio-economic correlates of health. Journal of Health Economics 23(4), 653-61. https://doi.org/10.1016/j.jhealeco.2004.04.004 
Ghislandi, S., Sanderson W. C., \& Scherbov, S. (2018). A Simple Measure of Human Development: The Human Life Indicator. Population Development Review 45(1), 219-233. https://doi.org/10.1111/padr.12205

Hajnal, J. (1965). European Marriage Patterns in Perspective. In Glass, D.V. \& Eversley, D.E.C. (Eds.), Population in History. Essays in Historical Demography. Volume I: General and Great Britain (pp. 101-43). New Brunswick (U.S.A.): Aldine Transaction.

Haapala, P. (Ed.) (2018). Suomen rakennehistoria: Näkökulmia muutokseen ja jatkuvuuteen 1400-2000 [Structural History of Finland: Perspectives on Change and Continuity 1400-2000]. Tampere: Vastapaino.

Hasell, J., \& Roser, M. (2019). How do we know the history of extreme poverty? Retrieved June 9, 2019, from Our World in Data Website: https://ourworldindata.org/extreme-history-methods

Heikkinen, S. (1997). Labour and the Market: Workers, Wages and Living Standards in Finland, 1850-1913. Helsinki: The Finnish Society of Sciences and Letters and The Finnish Academy of Science and Letters.

Helliwell, J. F., Layard, R., \& Sachs, J. D. (2019). World Happiness Report 2019. New York: Sustainable Development Solutions Network.

Hellstrand, J., Nisén, J., \& Myrskylä, M. (2019). All-time low period fertility in Finland: drivers, tempo effects, and cohort implications. MPIDR Working Paper 2019-006. Rostock: Max Planck Institute for Demographic Research. https://doi.org/10.4054/MPIDR-WP-2019-006

Hjerppe, R. (1989). The Finnish Economy 1860-1985: Growth and Structural Change. Bank of Finland. Helsinki: Government Printing Centre.

Human Mortality Database. (2017). University of California, Berkely (USA) and Max Planck Institute for Demographic Research (Germany). Retrieved May 16, 2019 from HMD Website: www.mortality.org

Jutikkala, E. (1965). Finland's Population Movement in the Eighteenth Century. In Glass, D.V. \& Eversley, D.E.C. (Eds.), Population in History: Essays in Historical Demography. Volume II: Europe and the United States (pp. 549-569). New Brunswick (U.S.A.): Aldine Transaction. https://doi.org/10.4324/9781315127026-8

Kettunen, P. (2001). The Nordic Welfare State in Finland. Scandinavian Journal of History 26(3), 225-247. https://doi.org/10.1080/034687501750303864

Kokkinen, A. (2012). On Finland's Economic Growth and Convergence with Sweden and the EU15 in the 20th Century. Statistics Finland. Research Reports 258.

Koponen, J. \& Saaritsa, S. (Eds.) (2019). Nälkämaasta hyvinvointivaltioksi: Suomi kehityksen kiinniottajana [From Hunger to Welfare: Finland's Catching-up in Development]. Helsinki: Gaudeamus.

Koskinen, S., Martelin, Tuija, Notkola, I.-L., Notkola, V., \& Pitkänen, K. (Eds.). (1994). Suomen Väestö [Population of Finland]. Helsinki: Gaudeamus.

Kujala, A, \& Danielsbacka, M. (2019). Reciprocity in Human Societies: From Ancient Times to the Modern Welfare State. Palgrave Macmillan. https://doi.org/10.1007/978-3-319-96056-2

Laine, J, Fellman, S., Hannikainen, M., \& Ojala, J. (Eds.) (2019). Vaurastumisen vuodet: Suomen taloushistoria teollistumisen jälkeen [Years of prosperity: Finnish economic history after industrialization]. Helsinki: Gaudeamus.

Laine, T., \& Salmi-Niklander, K. (2018). Book Culture from Below in Finland. In P. Rabinowitz (Ed.), Oxford Research Encyclopedia of Literature. Oxford: Oxford University Press. https://doi.org/10.1093/acrefore/9780190201098.013.286

Lok-Dessallien, R. (2000). Review of Poverty Concepts and Indicators. Retrieved December 17, 2019 from:

https://pdfs.semanticscholar.org/a358/eb2139bf8c50b338863d0ecb63d4c6dedb21.pdf 
Ljadi, A. (2018). Theoretical Foundations to outline Human Well-being: Meta-analytic Literature Review for defining Empowered Life Years. IASA Working Paper. IIASA, Laxenburg, Austria: WP-18-002.

Lutz, W. (1987). Finnish Fertility since 1722: Lessons from an Extended Decline. Helsinki: Publications of the Population Research Institute Series D, No. 18, 1987.

Lutz W. (2017). Global Sustainable Development priorities 500 y after Luther: Sola schola et sanitate. Proceedings of the National Academy of Sciences 114 (27): 6,904-13. https://doi.org/10.1073/pnas.1702609114

Lutz, W. \& Goujon, A. (2004). Literate life expectancy: Charting the progress in human development. In Lutz, W., Sanderson, W. C., \& Scherbov, S. (Eds.). The End of World Population Growth in the 21st Century: New Challenges for Human Capital Formation and Sustainable Development, pp. 159-186, London: Earthscan.

Lutz, W., Butz, W. P., \& KC, S. (2014). World Population and Human Capital in the Twenty-First Century. Oxford: Oxford University Press.

https://doi.org/10.1093/acprof:oso/9780198703167.001.0001

Lutz, W. \& Klingholz, R. (2017). Education First! From Martin Luther to Sustainable Development. Sun Media. https://doi.org/10.18820/9781928357360

Lutz, W., Striessnig, E., Dimitrova, A., Reiter, C., Spitzer, S., \& Yildiz, D. (2019). Years of Good Life (YoGL): A wellbeing indicator designed to serve as sustainability criterion. Unpublished Manuscript submitted for publication. Luxenburg.

Maddison Project Database (2018). Bolt, J., Inklaar, R., de Jong, H., \& van Zanden, J. L. Rebasing 'Maddison': new income comparisons and the shape of long-run economic development. Maddison Project Working Paper, Nr. 10. Retrieved August 19, 2019 from Groningen Growth and Development Center Website: www.ggdc.net/maddison

Magnuson, K. (2012). Socioeconomic status and cognitive functioning: Moving from correlation to causation. WIREs Cognitive Science 3(3), 377-86. https://doi.org/10.1002/wcs.1176

Mani, A., Mullainathan, S., Shafir, E., \& Zhao, J. (2013). Poverty impedes cognitive function. Science 341(6149), 976-80. https://doi.org/10.1126/science.1238041

Michalos, A. C. (2017). Connecting the quality of life theory to health, well-being and education: The selected works of Alex C. Michalos. Springer. https://doi.org/10.1007/978-3-319-51161-0

Menegaki, A. N. \& Tugcu, C. T. (2017). Energy consumption and Sustainable Economic Welfare in G7 countries: A comparison with the conventional nexus. Renewable and Sustainable Energy Reviews 69, 892-901. https://doi.org/10.1016/j.rser.2016.11.133

Murray, C. J. \& Lopez, A. D. (2013). Measuring the global burden of disease. The New England Journal of Medicine 369(5), 448-457. https://doi.org/10.1056/NEJMra1201534

Myllyntaus, T. (1990). Education in the Making of Modern Finland. Discussion Paper No. 312, ETLA (The Research Institute of the Finnish Economy), Helsinki.

Myrskylä, M., Kohler, H.-P., \& Billari, F. (2009). Advances in development reverse fertility declines. Nature 460(7256), 741-43. https://doi.org/10.1038/nature08230

National Library of Finland. (2018). Digitalized Archive: Poor Relief Statistics. Retrieved June 19 from National Library Network Services : https://www.doria.fi/discover?filtertype_1=subject\&filter_relational_operator_1=equals\&filter_1 $=\mathrm{k} \% \mathrm{C} 3 \% \mathrm{~B} 6 \mathrm{yh} \% \mathrm{C} 3 \% \mathrm{~A} 4$ inhoito\&submit_ap ply_filter $=\&$ query $=\mathrm{k} \% \mathrm{C} 3 \% \mathrm{~B} 6 \mathrm{yh} \% \mathrm{C} 3 \% \mathrm{~A} 4$ inhoito\&scope $=10024 \% 2 \mathrm{~F} 67150 \& \mathrm{rpp}=10 \&$ sort by $=$ dc.date.issued_dt\&order $=$ asc

Nieminen, M. (1999). Väestötilastoja 250 vuotta: Katsaus väestötilaston historiaan vuosina 1749 1999. [250 Years of Population Statistics: An overview of the history of population statistics from 1749 to 1999]. Tilastokeskus. Retrieved December 27, 2018 from the Finnish National Library Archive: https://www.doria.fi/handle/10024/98780 
Official Statistics of Finland. (2018). Population in Finland 1750-2018. Retrieved July 23, 2019 from Statistics Finland Website: https://www.stat.fi/til/vaerak/2018/vaerak_2018_2019-0329_kuv_001_en.html

Official Statistics of Finland. (2019a). Population structure [e-publication]. Retrieved August 20, 2019 from Statistics Finland Website:

https://findikaattori.fi/verti/Graphserver.htm?Gedit=false\&ifile=../quicktables/findikaattori/vaes to/vaeston_ikarakenteen_kehitys\& $=200 \& y=150 \&$ lang $=1$

Official Statistics of Finland. (2019b). Households' consumption [e-publication]. Retrieved June 24, 2019 from Statistics Finland Website: https://www.stat.fi/til/ktutk/index_en.html

Ojala, J., Eloranta, J., \& Jalava, J. (Eds.). (2006). The Road to Prosperity: An Economic History of Finland. Helsinki: Suomalaisen Kirjallisuuden Seura.

O’Neill, B.C., Kriegler, E., Ebi, K.L., Kemp-Benedict, E., \& Riahi, K. (2017). The roads ahead: Narratives for shared socioeconomic pathways describing world futures in the 21 st century. Global Environmental Change 42, 169-180.

Ravallion, M. (2008). Poverty Lines. In S. N. Durlauf, \& L. Blume (Eds.), The New Palgrave Dictionary of Economics (Vols. 1-8, pp. 5068-73). https://doi.org/10.1057/978-1-349-951215_2541-1

Riahi, K., van Vuuren, D.P., Kriegler, E., Edmonds, J., O'Neill, B.C., Fujimori, S. et al. (2017). The Shared Socioeconomic Pathways and their energy, land use, and greenhouse gas emissions implications: An overview. Global Environmental Change 42, 153-168. https://doi.org/10.1016/j.gloenvcha.2016.05.009

Roikonen, P. \& Heikkinen, S. (2018). A Kuznets rise and a Piketty fall: Income inequality in Finland, 1865-1934. European Review of Economic History, 1-34.

Saarivirta, T., Consoli, D., \& Dhondt, P. (2012). The evolution of the Finnish health-care system early 19th Century and onwards. International Journal of Business and Social Science 3(6), 243-57.

Statistics Finland. (2018). Finland among the best in the world. Retrieved June 13, 2019, from Statistics Finland Website: http://www.stat.fi/tup/satavuotias-suomi/suomi-maailmankarjessa_en.html

Strömmer, A. (1969). Väestöllinen Muuntu-minen Suomessa [The Demographic Transition in Finland]. Finnish Yearbook of Population Research 11, 101-16.

Turpeinen, O. (1979). Fertility and mortality in Finland since 1750. Population Studies 33(1), 10114.

United Nations Population Division. (2019). World Population Prospects 2019, Online Edition. Department of Economic and Social Affairs, Population Division. Retrieved August 20, 2019 from UN Website: https://population.un.org/wpp/Download/Standard/Population/

Vattula, K. (1983). Suomen taloushistoria 3. Historiallinen tilasto [The economic history of Finland 3. Historical statistics]. Helsinki: Kustannusosakeyhtiö Tammi.

Veenhoven, R. (1996). Happy life expectancy: A comprehensive measure of quality-of-life in nations. Social Indicators Research 39(1), 1-58. https://doi.org/10.1007/BF01079395

Voutilainen, M. (2016). Poverty, Inequality and the Finnish 1860s Famine. Academic Dissertation, University of Jyväskylä.

Weinstein, M. C., Torrance, G., \& McGuire, A. (2009). QUALYs: The Basics. Value in Health 12, 5-9. https://doi.org/10.1111/j.1524-4733.2009.00515.x

Wittgenstein Centre. (2018). Wittgenstein Centre Human Capital Data Explorer Version 2.0. Retrieved June 17, 2019 from WIC Website: http://www.wittgensteincentre.org/dataexplorer

World Bank. (2017). World Development Indicators. Retrieved July 30, 2019 from The World Bank Website: https://data.worldbank.org/products/wdi 